\title{
How long should we treat porphyric patients?
}

\author{
Ikuo Yamamori \\ Department of Internal Medicine, The Japanese Red Cross Nagoya First Hospital, 3-35 Michishita-cho, Nakamura-ku, Nagoya 453-8511, Japan \\ (Correspondence should be addressed to Ikuo Yamamori; Email: yamamori@nagoya-1st.jrc.or.jp)
}

Acute attack in hepatic porphyrias (acute intermittent porphyria, variegate porphyria, and hereditary coproporphyria) is a rare, but potentially life-threatening, condition. Although every physician should be aware of these metabolic syndromes, the rarity and broad spectrum of the symptoms of porphyrias often lead to a delay in diagnosis. I read with interest an illustrative case report that recently appeared in this journal (1), in which De Block and colleagues reported a 38-year-old woman who suffered acute intermittent porphyria with premenstrual attacks. Intravenous hypertonic glucose with i.v. haem arginate (Normosang) brought about temporary relief of the symptoms. Luteinizing hormonereleasing hormone (LH-RH) analogue combined with a low-dose oestrogen patch was needed to prevent cyclic attacks. When LH-RH analogue treatment was withdrawn, 17 months after its commencement, premenstrual attacks recurred. Another course of combination treatment was therefore reinstituted, and the patient had not required admission to hospital for 3 years (1). It is my opinion that such combination treatment is an excellent way of giving LH-RH analogue in order to avoid drug side effects.

Very recently, we also reported a patient with hereditary coproporphyria, whose premenstrual exacerbation was successfully treated with LH-RH analogue alone (2). Bone demineralization occurred, because we did not include oestrogen in our treatment, and the drug was tapered carefully. Spontaneous menstruation recovered 2 months after cessation of LH-RH analogue treatment, which was given over a total of 64 months. Surprisingly, since then, the patient has experienced only minor symptoms, for a period of more than 1 year. Clonazepam, to prevent epileptic seizure, is the only medication she is now receiving. We should be aware that the natural course of porphyria is variable and that spontaneous remission frequently occurs $(3,4)$. As we do not know what is (are) the principal determinant(s) leading to symptomatic porphyria, I believe that we should always be sensitive as to whether current treatment given to each patient might be safely withdrawn.

\section{References}

1 De Block CEM, De Leeuw IH \& Van Gaal LF. Premenstrual attacks of acute intermittent porphyria: hormonal and metabolic aspects a case report. European Journal of Endocrinology 1999141 50-54.

2 Yamamori I, Asai M, Tanaka F, Muramoto A \& Hasegawa H. Prevention of premenstrual exacerbation of hereditary coproporphyria by gonadotropin-releasing hormone analogue. Internal Medicine 199938 365-368.

3 Kappas A, Sassa S, Galbraith RA \& Nordmann Y. The porphyrias. In The Metabolic and Molecular Bases of Inherited Disease, edn 7 , ch 66, pp 2103-2159. Eds Scriver CR, Beaudet AL, Sly WS \& Valle D. New York: McGraw-Hill, 1995.

4 Kauppinen R \& Mustajoki P. Prognosis of acute porphyria: occurrence of acute attacks, precipitating factors, and associated diseases. Medicine 199271 1-13.

Received 11 October 1999

Accepted 4 November 1999 